\title{
Therapeutics
}

\section{Review: the levonorgestrel releasing intrauterine system prevents more pregnancies than intrauterine devices (IUDs) $\leqslant 250 \mathrm{~mm}^{2}$ but not IUDs $>250 \mathrm{~mm}^{2}$}

French RS, Cowan FM, Mansour D, et al. Levonorgestrel-releasing (20 mg/day) intrauterine systems (Mirena) compared with other methods of reversible contraceptives. BJOG 2000 Oct;107:1218-25.

QUESTION: In women of reproductive age, is the levonorgestrel releasing $(20 \mu \mathrm{g} / \mathrm{d})$ intrauterine system (LNG-20) more effective and tolerable than other reversible contraceptive methods?

\section{Data sources}

Studies were identified using Medline, EMBASE/ Excerpta Medica, PsycLIT, POPLINE, Cochrane Controlled Trials Register, and specialist databases between January 1974 and July 1998. Bibliographies of relevant articles were also reviewed. Experts in the field and organisations were contacted for unpublished data.

\section{Study selection}

Randomised controlled trials were selected if participants were women of reproductive age, they compared LNG-20 with another reversible contraceptive, and they had predetermined outcomes.

\section{Data extraction}

Data were extracted on predetermined outcomes of pregnancy as a result of method or user failure and continuation of contraceptive method. Data on these outcomes were extracted when either number of events per women months or single decrement life table probabilities were reported.

\section{Main results}

5 studies met the inclusion criteria. LNG-20 was compared with 2 groups of intrauterine devices (IUDs), categorised by the surface area of the copper wire: $\leqslant 250$ $\mathrm{mm}^{2}$ (Nova-T, CuT 200, and CuT 220 IUDs) and $>250$ $\mathrm{mm}^{2}$ (CuT $380 \mathrm{Ag}$ IUD). At 5 years of follow up, LNG-20 was more effective than IUDs $\leqslant 250 \mathrm{~mm}^{2}$ for preventing unplanned pregnancy (rate ratio [RR] 0.08, 95\% CI 0.04 to 0.18 ) but not more effective than IUDs $>250 \mathrm{~mm}^{2}$ (RR 0.66, CI 0.25 to 1.75) (table). Overall, continued use was more likely with LNG-20 than with IUDs $\leqslant 250 \mathrm{~mm}^{2}$ (RR 1.16, CI 1.02 to 1.31) and equally as likely with IUDs $>250 \mathrm{~mm}^{2}$ (RR 0.97, CI 0.83 to 1.14) (table). LNG-20 users were more likely to discontinue use because of hormonal side effects than were users of IUDs $\leqslant 250$ $\mathrm{mm}^{2}$ (RR 5.2, CI 1.3 to 20.3) and IUDs $>250 \mathrm{~mm}^{2}$ (RR 4.2, CI 2.0 to 9.0 ). LNG-20 users were also more likely to discontinue use because of amenorrhea than were users of IUDs $\leqslant 250 \mathrm{~mm}^{2}$ (RR 29.2, CI 1.7 to 488) and IUDs $>250 \mathrm{~mm}^{2}$ (RR 48.9, CI 16.9 to 141$)$.

\section{Conclusions}

In women of reproductive age, the levonorgestrel releasing $(20 \mu \mathrm{g} / \mathrm{d})$ intrauterine system (LNG-20) is more effective than intrauterine devices (IUDs) $\leqslant 250$ $\mathrm{mm}^{2}$ but as effective as IUDs $>250 \mathrm{~mm}^{2}$ for preventing pregnancy. LNG-20 is more likely to lead to discontinued use because of hormonal side effects and amenorrhea.

Levonorgestrel releasing $(20 \mu \mathrm{g} / \mathrm{d})$ intrauterine system $(L N G)$ v intrauterine devices $\leqslant 250$ $\mathrm{mm}^{2}(I U D \leqslant 250)$ or $>250 \mathrm{~mm}^{2}$ (IUD $\left.>250\right)$ in women of reproductive age at 5 years of use*

\begin{tabular}{cllll} 
Outcomes & Comparison & Event rates & RRR (95\% CI) & NNT:5 (CI) \\
Pregnancy & LNG $v$ IUD $\leqslant 250 \dagger$ & $0.009 \% v 0.11 \%$ & $92 \%(81$ to 97$)$ & 17 (13 to 26$)$ \\
\hline & LNG $v$ IUD $>250$ & $0.017 \% v 0.026 \%$ & $34 \%(-74$ to 75$)$ & Not significant \\
\hline $\begin{array}{c}\text { Continued } \\
\text { use }\end{array}$ & LNG $v$ IUD $\leqslant 250 \dagger$ & $1.11 \% v 0.96 \%$ & $16 \%(2$ to 31$)$ & $12(7$ to 61$)$ \\
\hline & LNG $v$ IUD $>250$ & $0.85 \% v 0.88 \%$ & $3 \%(-14$ to 17$)$ & Not significant \\
\hline
\end{tabular}

NNT:5 = NNT for a 5 year period of use. Other abbreviations defined in glossary; RRR, RBI, RBR, NNT, NNH, and $\mathrm{Cl}$ calculated from data in article.

†2 studies were meta-analysed using a fixed-effects model and reported weighted event rates; other comparisons were based on 1 study.

\section{COMMENTARY}

The systematic review by French $e t$ al addresses an important clinical question. The study methods reported were appropriate, and the search for relevant studies was comprehensive. The willingness by volunteers to be randomly allocated, however, implies that either contraceptive method was acceptable. The copper IUD comparative studies would therefore be unlikely to include women with heavy or painful menses, who are most likely to benefit from the "side effects" of LNG-20 (ie, reduction of menstrual flow and pain). Some studies also noted the importance of pre-insertion counselling to reduce concern about amenorrhea or the occurrence of irregular bleeding in the early months of use.

The category of IUDs $\leqslant 250 \mathrm{~mm}^{2}$ could be misleading because the only studies that were analysed related to the CuT $380 \mathrm{Ag}$ IUD, which has copper on the side arms and in the centre. No available comparisons existed with other high copper load devices positioned only centrally (eg, Multiload 375). The distinction in the positioning of the copper may be one reason why the CuT $380 \mathrm{Ag}$ IUD has such low pregnancy rates.

This review has a broader title than that of the abstract because a search was made for comparison with all reversible methods. Only 1 study not using a copper IUD was identified as eligible. This was a 3 year comparison with Norplant 2 that involved only 200 women and found no significant difference in measured outcomes other than fewer removals of devices because of bleeding with LNG-20.

The LNG-20 and the CuT 380 Ag IUD are equally effective and acceptable for women with normal menses. Questions remaining include which women are likely to benefit from a specific choice of 1 device or the other and the issue of cost effectiveness. Rosemary Kirkman, MB, ChB Palatine Centre Manchester, UK 